\title{
Presentación histopatológica-Inmunohistoquímica de Sarcoma histiocítico diseminado en canino. Reporte de caso
}

\author{
The Histopathologic -Immunohistochemical presentation \\ of Disseminated Canine Histiocytic Sarcoma. Case report
}

\section{Apresentação histopatológica-imunoistoquímica de Sarcoma histiocítico disseminado em canino: Estudo de caso}

\section{Karl A. Cinoderis - Aponte ${ }^{1 *}$, Julietha E. Ochoa - Amaya ${ }^{2 *}$}

\author{
MVZ \\ MVZ, MSc \\ Facultad de Ciencias Agropecuarias y Recursos Naturales, Escuela de Ciencias Animales, Universidad de los Llanos \\ Email: adolfmvz@gmail.com
}

Recibido: mayo 30 de 2011

Aceptado: noviembre 30 de 2012

\section{Resumen}

El sarcoma histiocítico diseminado (SHD), Ilamado también histiocitosis maligna, es una neoplasia rara en perros y de etiología desconocida. Es caracterizada por proliferación neoplásica maligna de macrófagos en diferentes órganos y la forma diseminada ocurre principalmente en órganos del sistema mononuclear fagocítico como hígado, bazo, ganglios linfáticos e intestino delgado. Los primeros relatos de SHD se describen en perros raza Bernese Mountain, no obstante, se reporta en otras razas como Rottweilers y Retrievers. Existen evidencias del origen de SHD por predisposición genética y en perros de mediana edad, aunque no está limitado a estas razas y puede ocurrir esporádicamente en cualquier raza. El SHD comúnmente se origina de la piel o del tejido subcutáneo pero algunos casos pueden originarse de tejidos profundos. La presentación de SHD es difícil de establecer porque las lesiones con frecuencia ocurren en sitios ocultos y es solo reconocida después de que los signos clínicos aparecen, entre estos anorexia, pérdida de peso, letargo, linfadenopatia y hepatoesplenomegalia son comunes y otros signos dependen de los órganos involucrados. Histológicamente SHD es pobremente demarcado y la proliferación celular resulta en pérdida de la arquitectura normal del tejido. Conformado por una mezcla predominante de células redondas y/o células ahusadas. Muchos tumores incluyen células gigantes y multinucleadas que pueden ser numerosas o no. El diagnostico del SHD es basado en histopatología e Inmunohistoquímica. El propósito de este reporte es documentar el caso de SHD en un canino hembra Labrador Retriever, con localización en la lengua y cavidad oral, presentándose como masas nodulares tumefactas y ulceradas multifocales de $1 \mathrm{~cm}$ de diámetro. Se tomaron muestras de tejido y se fijaron en formalina buffer $10 \%$ para estudio histopatológico rutinario. Los resultados incluyeron: En lengua observación de áreas compuestas por células histiociticas pleomórficas sustentadas por tejido conjuntivo de citoplasma eosinofílico de abundante a escaso con o sin vacuolas y numerosas células binucleadas y multinucleadas de citoplasma escaso con núcleos pleomórficos basofílicos con uno o dos nucleolos evidentes, también se observaron de cinco a seis figuras mitóticas por campo. Las características histológicas particulares de las lesiones observadas permitieron clasificar microscópicamente el tumor como sarcoma histiocítico diseminado concordando con las descripciones dadas por varios autores para SHD en esta y otras razas.
\end{abstract}

Palabras claves: canino, histiocitosis maligna, neoplasia mesenquimal, tumor células redondas. 


\begin{abstract}
Disseminated histiocytic sarcoma (DHS), also called malignant histiocytosis is a rare neoplasm in dogs and unknown etiology. It is characterized by malignant neoplastic proliferation of macrophages in various organs and the disseminated form occurs primarily in mononuclear phagocytic system organs like liver, spleen, lymph nodes and small intestine. First reports of DHS are described in Bernese Mountain Dogs, however, has been reported in other breeds such as Rottweilers and Retrievers. There is evidence of the origin of genetic predisposition and DHS in middle-aged dogs, but not limited to these races and may occur sporadically in any race. The DHS commonly originates from the skin and subcutaneous tissue but some cases may originate from deep tissues. The presentation of DHS is difficult to establish because injuries often occur in hidden places and is only recognized after clinical signs appear, among them anorexia, weight loss, lethargy, lymphadenopathy, and hepatosplenomegaly are common, and other signs depend on the organs involved. Histologically DHS is poorly demarcated and cell proliferation results in loss of normal tissue architecture. A mixture predominantly composed of round cells or spindle cells. Many tumors include multinucleated giant cells may be numerous or not. The diagnosis of DHS is based on histopathology and Immunohistochemical. The purpose of this report is to document the case of DHS in a canine female Labrador Retriever, with location on the tongue and oral cavity, appearing as swollen and ulcerated nodular masses multifocal than $1 \mathrm{~cm}$ in diameter. Were taken tissue samples and fixed in 10\% buffered formalin for routine histopathology. Results included: Areas consist of pleomorphic histiocytic cells supported by connective tissue with abundant eosinophilic cytoplasm with or without small vacuoles and numerous binucleated cells and multinucleated scanty cytoplasm with basophilic pleomorphic nuclei with one or two evident nucleoli, also were observed five to six mitotic figures per field. The specific histologic features of the lesions observed microscopically allowed classify the tumor as disseminated histiocytic sarcoma agreeing with the descriptions given by several authors for DHS in this and other breeds.
\end{abstract}

Key words: canine, malignant histiocytocis, mesenchimal neoplasm, round cell tumor.

\title{
Resumo
}

O sarcoma histiocítico diseminado (SHD), também conhecido por histiocitoses maligna, é uma neoplasia rara em cachorros e de etiologia desconhecida. É caracterizada pela proliferação neoplásica maligna de macrófagos em diferentes órgãos. E sua forma disseminada ocorre principalmente em órgãos do sistema mononuclear fagocítico, como fígado, baço, gânglios linfoides e intestino delgado. Os primeiros relatos do SHD se descrevem em cachorros da raça Bernese Mountain, não obstante, se reporta em outras raças como Rottweilers e Retrievers, podendo ocorrer, no entanto, em qualquer outra raça. Existem evidências da origem do SHD pela disposição genética e em cachorros de meia idade. Neoplasia que geralmente se origina da pele e do tecido subcutâneo, mas que em alguns casos pode originar-se dos tecidos profundos. A apresentação do $\Sigma \mathrm{H} \Delta$ é de difícil reconhecimento, devido às lesões ocorrer frequentemente em lugares ocultos e só reconhecidas após o aparecimento de sinais clínicos como: anorexia, perda de peso, letargia, linfadenopatia e hepatoesplenomegalia. Histologicamente o SHD é pouco demarcado e a proliferação celular resulta em perda da arquitetura normal do tecido. Conformado por uma combinação predominante de células redondas e/ou fusiformes. Muitos tumores incluem células gigantes e multinucleadas que podem ser numerosas ou não. O diagnóstico do SHD é baseado em histopatologia e imunoistoquímica. O propósito deste resumo é documentar o caso de SHD em um canino fêmea Labrador Retriever, com localização na língua e cavidade oral, apresentando-se como massas nodulares tumefactas e ulceradas multifocais de 1 $\mathrm{cm}$ de diâmetro. Amostras do tecido foram coletadas e fixadas em formol tamponado a 10\% para estudo histopatológico rotineiro. Os resultados incluíram: na língua, observação de áreas compostas por células histiocíticas pleomórficas sustentadas por tecido conjuntivo de citoplasma eosinofílico de abundante a escasso, com ou sem vacúolos e numerosas células binucleadas e multinucleadas de citoplasma escasso, com núcleos pleomórficos basofílicos, com um ou dois nucléolos evidentes; também se observaram de cinco a seis figuras mitóticas por campo. As características histológicas particulares das lesões observadas permitiriam classificar microscopicamente o tumor como sarcoma histiocítico disseminado concordando com as descrições dadas por vários autores para SHD nesta e outras raças.

Palabras claves: canino, histiocitoses maligna, neoplasia mesenquimal, tumor de células redondas.

\section{Introducción}

Las enfermedades histiociticas han estado bajo intenso escrutinio en los últimos años (Jacobs et al 2002), por tanto reportes previos de enfermedades histiocíticas proliferativas han documentado un rango amplio de desordenes que presentan diferencias marcadas en cuanto a su comportamiento clínico y patogenia (Rosin et al 1986; Cotran et al 1999; Kerlin y Hendrick 1996; Affolter y Moore 2000, 2002; Sans 2001; Golschmidt y Hendrick 2002; Moore 2002, 2008).
La Histiocitosis sistémica maligna (HSM) es un sarcoma de tejidos blandos que puede ser confundido con el Sarcoma Histiocítico (SH). Reciente la Inmunohistoquímica (IHQ) y estudios moleculares demostraron que la HSM describe un grupo de sarcomas pleomórficos indiferenciados, por lo cual este término ha sido retirado en la nueva clasificación de World Health Organization (WHO). El término $\mathrm{SH}$ ha sido adoptado por incluir un espectro de tumores malignos de histiocitos neoplasicos que son inmunopositivos para los marcadores celulares de superficie CD18. El término de sarcoma 
histiocítico ha sido propuesto también para la forma diseminada conocida previamente como histiocitosis maligna (Constantino-Casas et al, 2011).

El sarcoma histiocítico diseminado (SHD) referido también como histiocitosis maligna (Moore 1984; Moore y Rosin 1986; Cotran et al 1999; Affolter 2004) es un tumor raro en perros (Azakami et al 2006) y es de etiología desconocida (Hardis y Ginn 2001). La histiocitosis maligna (HM) es una neoplasia histiocítica agresiva que surge en múltiples sitios simultáneamente (Moore 1984; Moore y Rosin 1986) y se caracteriza por la proliferación maligna de histiocitos o de sus precursores en diferentes órganos y sistemas (Chandra y Ginn 1999; Jacobs et al 2002; Shelly 2003). La HM o SHD es un tipo de tumor de células redondas, incluidos entre estos el tumor de células de mast, los linfomas, el tumor de células plasmáticas, el tumor venéreo transmisible y el tumor de origen histiocítico (Goldshimdt \& Hendrick 2002; Willard y Tvedten 2003). La Inmunohistoquímica para E-cadherina (ECAD) se ha utilizado para distinguir histiocitoma cutáneo canino de otras neoplasias de leucocitos ("los tumores de células redondas") pero la expresión IHQ de ECAD no diferencia el Histiocitoma cutáneo canino de otras neoplasias de células redondas, por lo cual es necesario usar otros marcadores (por ejemplo, MUM1 para los plasmacitomas, KIT para los tumores de mastocitos, CD3 y CD79a para los linfomas) en los caninos (Ramos-Vara, Miller, 2011). Los histiocitos son células presentadoras de antígenos como los macrófagos y las células dendríticas, ambos descendientes del precursor común CD34+ (Willard y Tvedten 2003) y de las células de langerhans (Oeilvie y Moore 1995).

El SHD cursa con afectación diseminada principalmente de los órganos del sistema mononuclear fagocítico tales como hígado, bazo, ganglios linfáticos e intestino delgado (Lisa 1997; Suzuki et al 2003). La presentación de HM es difícil de establecer porque las lesiones con frecuencia ocurren en sitios ocultos por ende su existencia es solo reconocida después de que los signos clínicos aparecen y el progreso de la enfermedad avanza, asimismo el tumor es capaz de hacer metástasis extendida, ocurriendo al mismo tiempo dos síndromes que se combinan clínicamente pero no siempre es posible diferenciar su origen verdadero pues este es de origen multicéntrico (Moore 1984).

Los desordenes histiocíticos que afectan a los perros han sido descrito desde los años setenta (Goldschmidt \& Shofer 1992; Constantino-Casas et al, 2011) y los primeros relatos de histiocitosis maligna fueron descritos en perros Bernese Mountain (Chandra y Ginn 1999; Jaffe 2001; Searcy 2001; Moore 2002) con un 25\% de frecuencia de presentación (Constantino-Casa,
2011), sin embargo esta condición también ha sido documentada en otras razas (Schmidt et al 1993; Scott et al 1995; Ramsey et al 1996; Valli et al 2002; Willard y Tvedten 2003; Affolter 2004; Khosravi y Del Castillo 2005; Azakami et al 2006) como Rottweleirs y Retrievers (Moore 1984, 2002; Goldschmidt y Shofer 1992; Cotran et al 1999; Hargis y Ginn 2001; Affolter 2004, Constantino-Casas et al, 2011). Existen evidencias de su origen por predisposición genética (Hargis y Ginn 2001; Searcy 2001), así como en perros de mediana edad (Goldschmidt y Shofer 1992; Jacobs et al 2002; Affolter 2004), aunque no está limitado a estas razas y puede ocurrir esporádicamente en cualquier raza (Hargis y Ginn 2001; Affolter 2004).

Las lesiones primarias de SHD ocurren en el bazo, en nódulos linfáticos, en pulmón, en médula ósea, en piel y subcutis especialmente de las extremidades (Goldschmidt y Shofer 1992; Affolter y Moore 2002 ConstantinoCasas et al, 2011). Los sitios secundarios son variados pero incluyen hígado y pulmón (con el bazo como sitio primario) y nódulo linfático hilar (con el pulmón como sitio primario) (Cotran et al 1999). En pulmón las lesiones macroscópicas halladas consisten en masas blancas firmes y solitarias que pueden reemplazar por completo a los lóbulos pulmonares o pueden encontrarse lesiones múltiples con distribución aleatoria (Wilson y Dungworth 2002). Los signos clínicos comunes incluyen anorexia, pérdida de peso y letargo (Goldschmidt y Shofer 1992; Searcy 2001, Constantino-Casas 2011), linfadenopatia generalizada y hepatoesplenomegalia (Cotran et al 1999; Searcy 2001).

Histopatológicamente el tumor esta pobremente demarcado y la proliferación celular comúnmente resulta en pérdida de la arquitectura normal del tejido (Goldschmidt y Shofer 1992). Las lesiones histológicas independientemente de la ubicación están compuestas por una población de células histiociticas pleomórficas que muestran típicamente vacuolas redondeadas en combinación con células mesenquimales engrosadas (Goldschmidt y Shofer 1992). Generalmente hay una marcada anisocariosis y anisocitosis con numerosas figuras mitóticas aberrantes (Goldschmidt \& Shofer 1992; Oeilvie y Moore 1995), también pueden presentarse infiltrados inflamatorios (Moore 1984; Searcy 2001). Puede ocurrir la fagocitosis de células rojas, leucocitos y de células tumorales, pero no es prevalente. En el bazo los histiocitos neoplásicos manifiestan una marcada eritrofagocitosis y los infiltrados obliteran la pulpa roja del bazo e invaden los senos de la pulpa roja (Moore 1984). Una forma agresiva de SH del bazo ha sido reportado en Flat Coated Retrievers, la presentación clínica y hallazgos fueron consistentes con la forma hemofagocítica de SH (Constantino-Ca- 
sas, 2011). Las malignidades histiocíticas son funcionalmente divididas en tumores de células dendríticas y tumores de macrófagos, los cuales son asociados con el síndrome hemofagocítico (Lisa 1997; Olsen 2003).

El diagnostico del sarcoma histiocítico está basado en los hallazgos patológicos incluyendo proliferación difusa de grandes histiocitos anaplásicos, células gigantes multinucleadas y ocasionalmente eritrofagocitosis y/o células debridadas (Azakami et al 2006), sin embargo el diagnostico definitivo frecuentemente es muy difícil de hacer debido a la presencia de infiltrados de macrófagos y a las características inmaduras de las células tumorales (Oeilvie y Moore 1995). Aunque se use herramientas diagnosticas como la citología y la histopatología, histopatológicamente, muchos de esos tumores de células redondas son pobremente diferenciados, anaplasicos, la histogénesis de ellos es difícil de determinar con H\&E. Los histiocitos son un grupo heterogéneo de células con diferente morfología y características funcionales (Constantino-Casas et al, 2011), es necesario el uso de otras ayudas diagnosticas tales como microscopia electrónica, inmunohistoquímica y los niveles de ferritina (Trost et al 2008). La tinción Inmunohistoquímica es una técnica usada para identificar con precisión la célula de origen en tumores mal diferenciados como el SH. La Identificación de histiocitos se puede lograr con las moléculas que participan en la presentación del antígeno, tales como moléculas de MHCll y las b2 integrinas CD11d/CD18. En el bazo normal, la expresión de la integrina b2 por histiocitos es altamente expresada. CD11d es exclusivamente expresado por los macrófagos de la pulpa roja más allá de la zona marginal, mientras que en condiciones neoplásicas, la expresión CD11d se convierte en un total desorden (Constantino-Casas et al, 2011).

Las caderinas son moléculas de adhesión transmembranales homofílicas calcio dependientes, con funciones en la morfogénesis y el mantenimiento de la integridad del tejido. En la epidermis, la E-cadherina (ECAD) está presente en los queratinocitos basales y otros, su anclaje de dominio es intracitoplasmático a otras proteínas del citoesqueleto, como catenina y actina. Además de su expresión en la epidermis, ECAD se expresa en los órganos derivados de epitelios, las células de Langerhans, los timocitos inmaduros, algunos subtipos de linfocitos, las células de mast, eritroides nucleados, queratinocitos epidérmicos y de Langerhans. Sin embargo una reacción fuerte de inmunoreactividad para ECAD en un trabajo de diagnóstico rutinario de plasmacitoma cutáneo canino se solicita una evaluación de la reactividad cruzada de ECAD para tumores de células redondas no histiocíticas (plamacitomas, tumo- res de células de mast y linfomas no epiteliotropicos) (Ramos-Vara, Miller, 2011).

El tratamiento quirúrgico no es la mejor elección puesto que en el SHD ocurren múltiples metástasis siendo más a menudo la migración rápida al hígado. La respuesta a la quimioterapia no ha sido documentada y la enfermedad es rápidamente progresiva (de semanas a meses) llegando a la muerte o la eutanasia (Oeilvie y Moore 1995; Carioto 1997). El pronóstico depende del grado de infiltración y disfunción orgánica, sobre todo en la médula ósea, hígado y pulmones (Kelly 1970; Schmidt et al 1992). Es un gran desafío para los médicos veterinarios el diagnostico clínico del SHD así como la realización de un diagnostico diferencial pues esta neoplasia se asemeja mucho a otras enfermedades tumorales (Obs Pers).

Entendiendo que la presentación de este tumor es más frecuente en órganos del sistema mononuclear fagocítico el propósito de este reporte es documentar el caso de SHD, su expresión IHQ de antígenos localizados periféricamente en las células tumorales permitiendo la caracterización histológica e inmunohistoquímica del SHD, en un canino hembra Labrador Retriever con presentación tumoral en cavidad oral y lengua con metástasis pulmonar.

\section{Reporte de caso}

\section{Anamnesis}

En este informe se presenta el caso de un paciente canino hembra de la Raza: Retriever (Labrador Dorado) de una edad de 10 años con un de peso $26 \mathrm{~kg}$ cuyo motivo de consulta en un Hospital veterinario particular de la ciudad de Villavicencio, Meta (Colombia), fue salivación profusa, sangrado vaginal y emaciación, así como parto distócico una semana antes de la consulta en la Universidad de los Llanos. Al igual el propietario informó acerca de un tratamiento antibacteriano que se le instauró al animal 10 días anteriores a la consulta, con la finalidad de controlar una neumonía infecciosa.

\section{Hallazgos al examen clínico}

Al examen clínico la paciente estaba deprimida, postrada (estupor), con una condición corporal dos de cinco, una temperatura corporal de $38{ }^{\circ} \mathrm{C}$, con palidez de mucosas y con tiempo de llenado capilar de tres segundos, frecuencia cardiaca y frecuencia respiratoria muy aumentadas, presentaba sialorrea. Como hallazgos significativos se encontró aumento de los ganglios linfáticos a nivel general, una marcada disnea 
y taquicardia, estertores craneoventrales en ambos pulmones, bordes irregulares y anormalidades en lengua y masas nodulares multifocales de un centímetro de diámetro en cavidad bucal.

\section{Diagnóstico diferencial}

Como diagnóstico diferencial se tuvieron en cuenta todos los desordenes proliferativos malignos de histiocitos o de sus precursores entre estos los tumores de células redondas.

\section{Examen postmortem}

De acuerdo con el pronóstico y la mala evolución del paciente se realizó eutanasia del mismo seguida del respectivo examen de necropsia.

\section{Hallazgos macroscópicos}

Los principales hallazgos a la inspección externa fueron: masas nodulares multifocales, tumefactas y ulceradas de $1 \mathrm{~cm}$ diámetro en cavidad oral (ver figura $1 \mathrm{~A})$, pérdida del tejido lingual (ver figura $1 \mathrm{~A}$ ), halitosis y presencia de sarro dental (ver figura 1A). Edema y hemorragia petequial en epiglotis, así como presencia de secreción mucopurulenta en la glotis. Los pulmones se encontraron pálidos con zonas de atelectasia y masas nodulares multifocales de un centímetro de diámetro, se evidencio congestión en bordes lobulares. En estómago se presentaron hemorragias en la mucosa y secreción mucoserosa de color verde claro (ver figura 1C). El hígado se hallo muy congestionado, de color marrón oscuro y con apariencia marmorizada y escasas masas nodulares de un centímetro de diámetro. El corazón presento dilatación de las cuatro cámaras con ganglios linfáticos mediastínicos de coloración negra. En el bazo se presento congestión y con superficie rugosa capsular. Se encontró enterorragia y mucosa intestinal hiperémica. Los riñones estaban muy congestionados y tumefactos. Los ovarios estaban de color pálido y hubo presencia de un cuerpo lúteo en el ovario derecho. En la vagina se halló una secreción amarillo verdosa fétida. En el útero se encontraron dos fetos en proceso de autolisis.

\section{Hallazgos microscópicos}

Después de realizada la necropsia se tomaron muestras de las masas neoplásicas encontradas, estas se depositaron en formalina tamponada al $10 \%$ para el estudio histopatológico. Las muestras fueron procesadas y coloreadas con la técnica de rutina Hematoxilina y Eosina (H-E) para microscopia óptica. El diagnóstico histológico fue basado sobre características histológicas del tumor sobre la coloración de Hematoxilina y eosina.

Los estudios microscópicos revelaron un $\mathrm{SH}$ maligno en lengua (Figuras $2^{\underline{a}}$ y $2 \mathrm{C}$ ) con linfoadenitis mononuclear e hiperplasia folicular (Figura 2E), se observan células histiocíticas pleomórficas y células gigantes (Figura 2B), donde se aprecian las células anaplásicas histiocíticas con marcado pleomorfismo celular y con nucleolo evidente (Figura 2C). Se evidenció binucleación con núcleo arriñonado, vacuolas citoplasmáticas y nucleolos basófilos (Figura 2D), linfoadenitis mononuclear con hiperplasia folicular (Figura 2E). En células histiocíticas, Figuras de mitosis de 5 a 6 por campo (Figura 2F). En pulmón se observaron las mismas células descritas anteriormente.

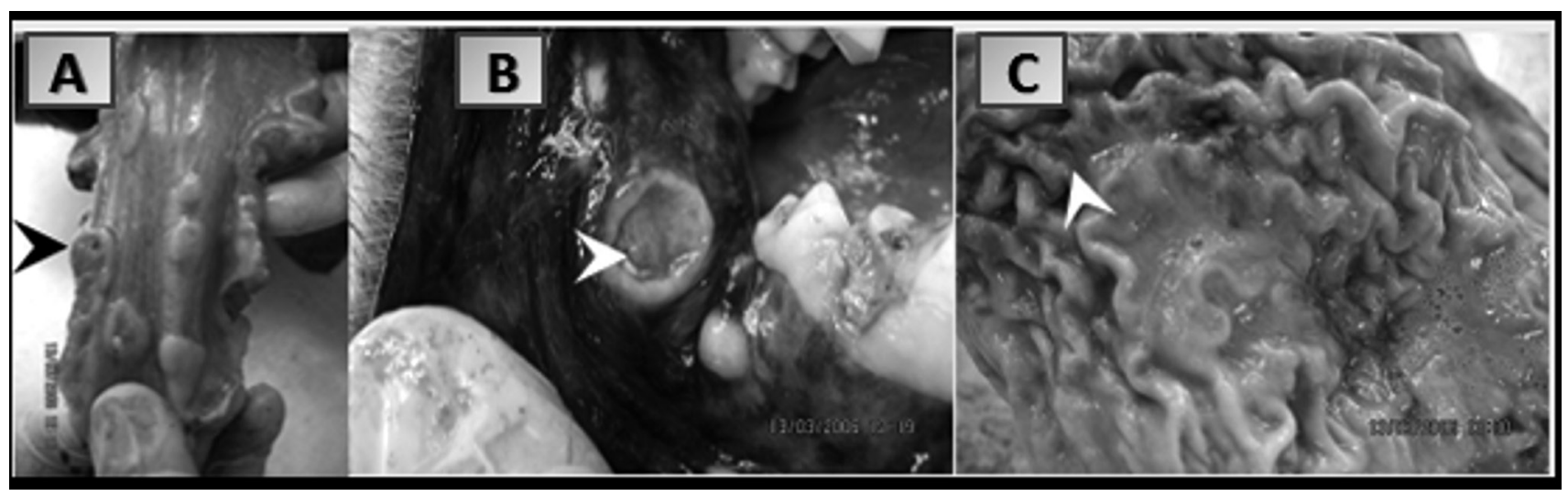

Figura 1. Masas tumorales múltiples ubicadas en cavidad oral y lengua. Perdida de la continuidad del tejido lingual [cabeza de flecha] (A). Masa tumoral ulcerada en la mucosa oral [cabeza de flecha] y sarro dental (B). Contenido estomacal y hemorragias multifocales en la mucosa gástrica [cabeza de flecha] (C). 


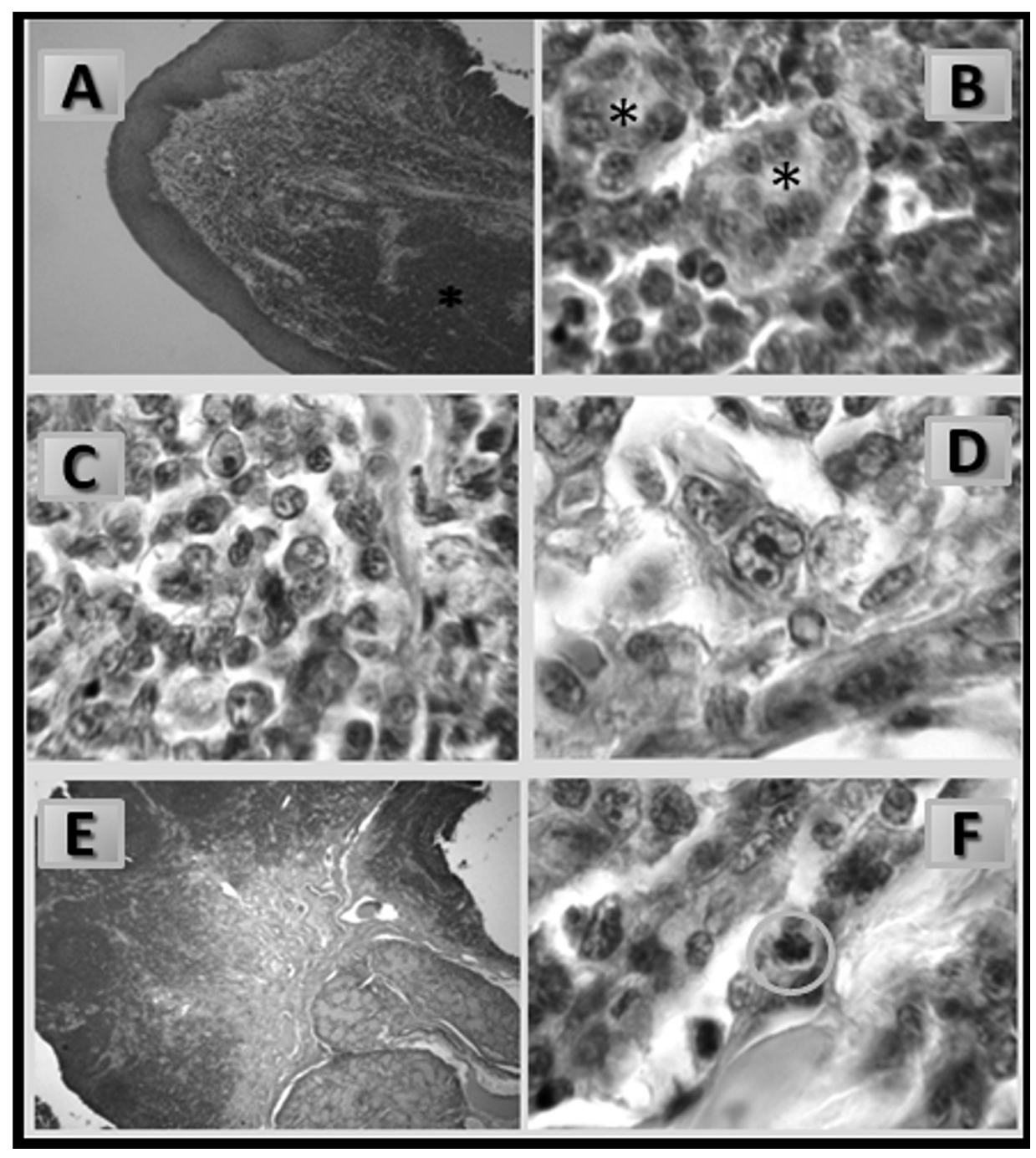

Figura 2. SHD en corte histológico de lengua. Células basófilas densamente agrupadas bajo el epitelio [*] (A). Proliferación de células histiocíticas y células gigantes $\left.{ }^{*}\right](B)$. Células histiocíticas anaplásicas basófilas con nucléolo evidente (C). Célula histiocítica pleomórfica con núcleo arriñonado y binucleolada (D). Linfoadenitis mononuclear e hiperplasia folicular linfoide (E). Figuras de mitosis en células histiocíticas (F).

\section{Inmunohistoquímica}

La IHQ fue hecha para confirmar el diagnóstico histopatológico de SHD. Para la IHQ de E Caderinas (ECAD) las secciones de tejido fijadas en formalina buferada y embebidas en parafina, fueron enviadas al laboratorio de Interfacultades de La Universidad Nacional de Colombia. La intensidad de la reacción IHQ para las ECAD fué semicuantitativa: 0 , no hay reacción, 1 , débil (10 al $20 \%$ de células positivas); 2 , moderada $(<50 \%$ de células positivas); 3 , fuerte (50\% de células positivas). La localización celular de ECAD se registró en la membrana plasmática, citoplasma o región paranuclear. Inmunomarcación nuclear no se observó. En la inmunohistoquimica, las células tumorales fueron positivas en un $10 \%$ o menos para las citoqueratinas, donde la intensidad de la reacción IHQ fue considerada débil.

Debido a la débil marcación para ECAD, se procedió a enviar el bloque parafinado al laboratorio de Patología del Hospital Universitario San Ignacio de la Universidad Javeriana de Colombia, se realizó IHQ para antígeno CD11. La marcación fue positiva en varias secciones del tejido tumoral. Por lo cual se confirmó el SHD en el paciente estudiado.

La inmunoreactividad del SHD del paciente en estudio para los antígenos CD11 y para las citoqueratinas es ilustrado en la Figura 3. 


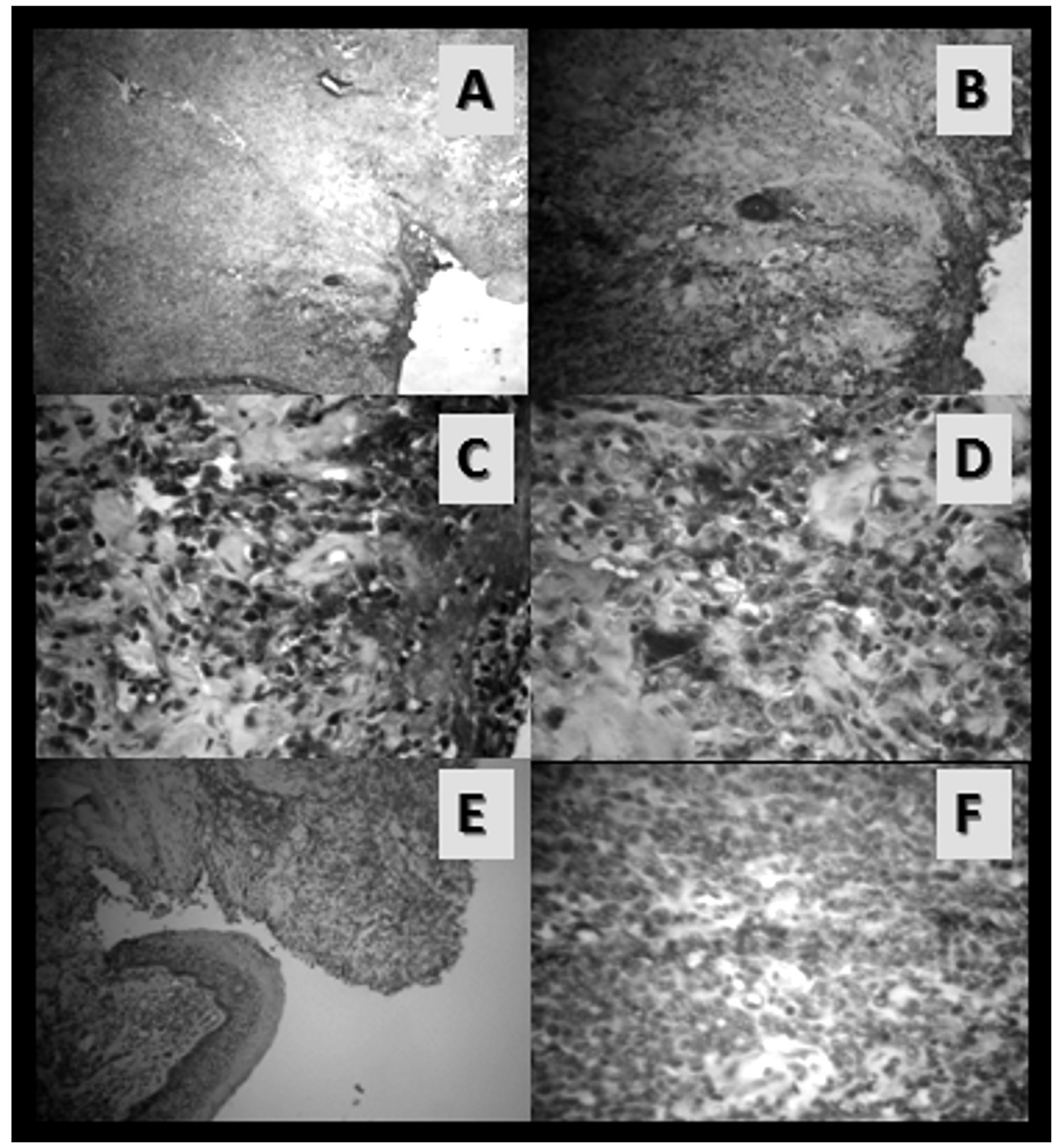

Figura 3. SHD en corte histológico de lengua. Inmunoreactividad para CD11 (A-D) y E caderina ECAD (E-F). Marcación para CD11 débil y difusa en casi toda la superficie del tumor, solamente hubo una marcación más intensa en una porción del tumor (A). Detalle de la reacción, la cual es localizada principalmente en la membrana plasmática y citoplasma celular neoplasico (B). Detalle de la inmunoreacción en la membrana citoplasmática y citoplasma, (C). Coloración citoplasmática granular color café oscuro en zona inmunoreactiva para CD11 (D). Débil marcación para E Caderina (ECAD) en el tumor, el epitelio estratificado plano de la lengua es positivo para ECAD, coloración café. (E). Inmunoreactividad débil de células histiocíticas para ECAD, coloración citoplasmática café, en forma lineal (F).

\section{Discusión}

La histiocitosis sistémica maligna o sarcoma histiocitico diseminado (SHD) es una enfermedad distinta de las otras enfermedades histiocíticas (Affolter y Moore 2000; Willard y Tvedten 2004), pues ésta es una patología multisistémica agresiva, caracterizada por la presencia de masas tumorales múltiples en vísceras, mas notablemente en el bazo, hígado, pulmón, riñón, nódulos linfáticos y hueso (Lisa 1997; Carlyle et al 1997; Affolter y Moore 2000; Shelly 2003), pero los tumores en piel pueden aparecer solos o como parte de la enfermedad multiorgánica (Goldschmidt y Hendrick 2002). Esta se desarrolla comúnmente al cabo de una semana o dos y puede aparecer como masas elevadas, móviles, no encapsuladas, pobremente circunscritas y 
lobuladas ya sea en la dermis o subcutis (Azakami et al 2006). Las tumoraciones pueden varíar de 1 a $3 \mathrm{~cm}$ de diámetro y frecuentemente son ulceradas (Goldschmidt y Shofer 1992).

Conforme a las descripciones dadas por varios autores (Goldschmidt y Shofer 1992; Schmidt et al 1992, 1993; Hayden et al 1993; Peaston et al 1993; Uno et al 1993; Kerlin y Hendrick 1996; Lisa 1997; Chandra y Ginn 1999; Cotran et al 1999; Jaffe 2001; Affolter y Moore 2002; Moore 2002), al igual que en el presente reporte de caso podría proporcionarse una fuerte evidencia de la inherencia de la raza Retriever para padecer de SHD, que permite conjeturar su posible predisposición genética a esta neoplasia.

Lisa (1997), Searcy (2001) Fulmer y Mauldin (2007) reportaron que los perros que padecen de SHD presentan signos clínicos como anorexia, letargia, pérdida de peso y anemia, donde los tres primeros síntomas fueron evidenciados en el presente caso (ConstantinoCasas et al, 2011).

Microscópicamente se diagnosticó el SHD en el tejido lingual por la observación de áreas compuestas por células histiociticas pleomórficas de ovales a poligonales, algunas con núcleos ovoides a reniformes con mono o binucleolos bien evidentes, así como abundante citoplasma eosinofílico con o sin vacuolas. Adicionalmente se observó la presencia de tejido conjuntivo como soporte celular así como numerosas células binucleadas y multinucleadas con citoplasma escaso y de 5 a 6 figuras mitóticas por campo. La descripción histopatológica de este reporte concuerda con las características histológicas del histiocitosis maligna descritas por Carlyle et al (1997), Valli et al (2002), Willard y Tvedten (2004), Azakami et al (2006) y Trost et al (2008), (Constantino-Casas et al, 2011).

En la necropsia de los animales afectados se ven involucrados muchos órganos y esto depende del curso de la enfermedad (Moore 1984; Schmidt et al 1992), no obstante en el presente caso pocos órganos estuvieron implicados y la muerte del animal probablemente sobrevino como una consecuencia de la posible septicemia debido a la distocia y posterior autolisis fetal intrauterina.

La histiocitosis maligna infrecuentemente ocurre en piel (Goldschmidt y Hendrick 2002; Shelly 2003) debido a que las células implicadas en esta enfermedad pertenecen principalmente al sistema mononuclar fagocítico (Lisa 1997), por lo tanto el presente hallazgo de masas tumorales en cavidad oral y lengua con respectiva descripción histopatológica y confirmación IHQ característica de SHD podría ser el primer reporte documentado en la raza Retriever para este tumor. No obstante, existen otros reportes que indican la presentación infrecuente de SHD en mucosa nasal, parpados y esclerótica (Jacobs et al 2002, Constantino- Casas 2011).

Aunque es bien descrito que el diagnóstico para el SHD puede basarse solamente en análisis histopatológicos, es importante resaltar que se requieren de estudios inmunohistoquímicos para distinguir los desordenes proliferativos histiociticos de algunas otras neoplasias de células redondas, debido a que basándose en estudios inmunofenotípicos esos histiocitos malignos son positivos para CD1, CD11c, MHCII, CD4 y THY-1 mientras que las células del histiocitoma son negativas para CD4 y THY-1 y los linfocitos son positivos para CD3, CD8, y TCR ${ }^{\alpha \beta T}$ (Jacobs et al 2002). Se realizó IHQ para antígeno ECAD y para CD11 y debido a la débil marcación para ECAD, y en virtud de los resultados obtenidos por Ramos-Vara y Miller (2011) donde la expresión IHQ para ECAD no es exclusiva para leucocitos de histiocitomas cutáneos y no distingue entre los tumores de células redondas y aquellos de origen histiocítico, se procedió a hacer inmunomarcación para CD11, la marcación fue positiva en varias secciones del tejido tumoral, estando de acuedo con Constantino-Casas (2011), donde él describe que la IHQ es una técnica que permite identificar con exactitud el origen celular en tumores pobremente diferenciados como el $\mathrm{SH}$. La identificación de histiocitos puede ser llevada a cabo con moléculas relacionadas con presentación de antígenos como Complejo Mayor de Histocompatibilidad II (MHC II) y expresión de b2 integrinas CD11d/ CD18, como sucedió en éste paciente que tuvo inmunomarcación positiva para antígeno CD11. Por lo que se confirmó el SHD en el paciente estudiado.

\section{Conclusiones}

El SHD es una enfermedad de difícil diagnostico, con varias manifestaciones clínicas y procesos anatomopatológicos que pueden confundirse con otras entidades tumorales. Debido a que muy pocos reportes histopatológicos han sido documentados en lengua y cavidad oral, el objetivo de este trabajo fue presentar el caso de SHD en un canino hembra Labrador retriever, caracterizar la neoplasia histológica e inmunohistoquímicamente, describiendo las características morfológicas y fenotípicas de $\mathrm{SH}$ en lengua compuestas por proliferación de células histiocíticas pleomórficas binucleadas y multinucleadas con 5 a 6 figuras mitóticas por campo y nucléolos evidentes, 


\section{Agradecimientos}

Los autores agradecemos al laboratorio de Histopatología de la Universidad de los Llanos y a la histotecnóloga Andrea Hernández de dicho laboratorio.

\section{Referencias}

Affolter VK, Moore PF. Canine cutaneous and systemic histiocytosis: reactive histiocytosis of dermal dendritic cells. Am J Dermatopathol. 2000; 22 (1): 40-8.

Affolter VK, Moore PF. Localized and disseminated histiocytic sarcoma of dendritic cell origin in dogs. Vet Pathol. 2002; 39 (1): 74-83.

Affolter VK. Histiocytic Proliferative Diseases in Dogs and Cats. En: Modiano J.F. Proceedings 29th Congress of the World Small Animal Veterinary Association. 2004; Rhodes, Greece.

Azakami D, Bonkobara M, Washizu T, lida A, Kondo M, et al. Establishment and biological characterization of canine histiocytic sarcoma cell lines. J Vet Med Sci. 2006; 68 (12): 1343-6.

Carioto L. Malignant histiocytosis in a Bernese mountain dog presenting as a mandibular mass. Can Vet J. 1997; 38 (2): 105-107.

Carlyle TC, Duncan RD, King NW. Veterinary Pathology. 6 ed. (USA): Wiley-Blackwell; 1997. p 868, 1040.

Chandra AM, Ginn PE. Primary malignant histiocytosis of the brain in a dog. J Comp Pathol. 1999; 121(1): 77-82.

Constantino-Casas F, Mayhew D., Hoather TM, Dobson JM. The Clinical Presentation and Histopathologic-Immunohistochemical Classification of Histiocytic Sarcomas in the Flat Coated Retriever. Veterinary Pathology 2011; 48(3) 764-771.

Cotran RS, Kumar V, Collins T, Robbins SL. Robbins pathologic basis of disease. 6 ed. Michigan (USA): W.B Saunders company; 1999. p 701.

Fulmer A, Mauldin G. Canine histiocytic neoplasia: An overview. Can Vet J. 2007; 48(10): 1041-1050.

Goldschmidt MH, Shofer FS. Skin tumor of the dog \& cat. New York (USA): Pergamon Press Oxford. 1992. p 131-141.

Golschmidt MH, Hendrick MJ. Tumors of the skin and soft tissues. En: Meuten DJ. Tumors in domestic animals. 4 Ed. lowa (USA): lowa state press; 2002. p 111.

Hargis AM, Ginn PE. Integumentary system. En: McGavin MD, Carlton WW, Zachary JF. Thompson's special veterinary pathology. 3 Ed. Missouri (USA): Mosby; 2001. p 591.

Hayden DW, Waters DJ, Burke BA, Manivel JC: Disseminated malignant histiocytosis in a Golden Retriever: clinicopathologic, ultrastructural, and immunohistochemical findings. Vet Pathol. 1993; 30 (3): 256-264.

Jacobs RM, Messick JB, Valli VE. Tumors of the hemolymphatic system. En: Meuten DJ. Tumors in domestic animals. 4 Ed. lowa (USA): lowa state press; 2002. p 170-172.

Jaffe ES. Pathology and genetics of tumours of haematopoietic and lymphoid tissues. World Health Organization classification of tumours IARC/World Health Organization Classification of Tumours Series - Volumen 3. Lyons (USA): IARC Press; 2001. p 230-5, 273-89.

Kelly DF. Canine cutaneous histiocytoma. A light and electron microscopic study. Pathol Vet. 1970; 7 (1):12-27.

Kerlin RL, Hendrick MJ. Malignant fibrous histiocytoma and malignant histiocytosis in the dog. Convergent or divergent phenotypic differentiation? Vet Pathol. 1996; 33 (6): 713- 716.

Khosravi SP, Del Castillo AR. Sarcoma histiocítico: caso clínico y revisión de la literatura. An. Med. Interna. 2005; 22 (4): 185-187.

Lisa C. Malignant histiocytosis in a Bernese mountain dog presenting as a mandibular mass. Can Vet J. 1997; 38 (2): 105-107.

Moore PF, Rosin A: Malignant histiocytosis of Bernese mountain dogs. Vet Pathol. 1986; 23 (1):1-10.

Moore PF. Canine histiocytic neoplasia: cell lineages and disease classification. En: Modiano JF. Genes, Dogs and Cancer. 2nd Annual Canine Cancer Conference; 2002 Sep 18; Aurora, OH, USA.

Moore PF. Histiocytic Sarcoma Complex. Canine Histiocytosis site. School of Veterinary Medicine University of California Davis. [Acceso en línea Junio 2008]. Disponible en URL: http://www. histiocytosis.ucdavis.edu/

Moore PF. Systemic histiocytosis of Bernese mountain dogs. Vet Pathol. 1984; 21 (6): 554-563.

Oeilvie GK, Moore AS. Managing the Veterinary Cancer Patient: A Practice Manual. New Jersey (USA): Veterinary Learning Systems Inc; 1995. p 499-500.

Olsen K. Malignant histiocytosis in a cat. Senior seminar paper. Cornell University college of Veterinary Medicine. 2003. [Acceso en línea Junio 2008]. Disponible en URL: http://test-ir.library. cornell.edu/bitstream/1813/2765/1/2003\%20Olsen.pdf

Peaston AE, Munn RJ, Madewell BR. Clinical vignette. A 7-year-old Bernese Mountain Dog with anemia. J Vet Intern Med. 1993; 7 (2): 101-103.

Ramos-Vara J, Miller MA. Immunohistochemical Expression of E-cadherin Does Not Distinguish Canine Cutaneous Histiocytoma. Veterinary Pathology 2011; 48(3) 758-763

Ramsey IK, McKay JS, Rudorf H, Dobson JM: Malignant histiocytosis in three Bernese Mountain Dogs. Vet Rec. 1996; 138 (18): $440-444$.

Rosin A, Moore P, Dubielzig R: Malignant histiocytosis in Bernese Mountain Dogs. J Am Vet Med Assoc. 1986; 188 (9): 1041 1045.

Sans J. Hematología Clínica. 4 ed. Madrid (España): Elsevier Science. 2001. p 547-64. Citado en: Ruiz O, Quinones W, Misad O, et al. Histiocitosis maligna: Reporte de un caso. An. Fac. med. 2004; 65 (4): 255-259.

Schmidt ML, Rutteman G, Wolvekamp P. Canine malignant histiocytosis $(\mathrm{MH})$ : clinical and radiographic findings. Tijdschr Diergeneeskd. 1992; 117 suppl(1): 43-44. 
Schmidt ML, Rutteman GR, van Niel MH, Wolvekamp PT. Clinical and radiographic manifestations of canine malignant histiocytosis. Vet Q. 1993; 15 (3): 117-120.

Scott DW, Miller WH, Griffin CE. En: Muller GH, Scott DW, Kirk RW, Miller WH, Griffin CE. Muller \& Kirk's Small Animal Dermatology. 6 Ed. Philadelphia (USA): WB Saunders; 1995. p $1355-1357$.

Searcy GP. The hemopoietic system. En: McGavin MD, Carlton WW, Zachary JF. Thompson's special veterinary pathology. 3 Ed. Missouri (USA): Mosby; 2001. p 351.

Shelly SM. Cutaneous lesions. Vet Clin Small Anim. 2003; 33 (1):146.

Suzuki M, Uchida K, Morozumi M, Yanai T, Nakayama H, et al. A comparative pathological study on granulomatous meningoencephalomyelitis and central malignant histiocytosis in dogs. J Vet Med Sci. 2003; 65 (12): 1319-24.

Trost ME, Ramos AL, Masuda LE, dos Anjos LB, Cunha M, Graça D. Malignant histiocytosis in a cat - Case report. Braz J Vet Pathol; 2008; 1(1): 32-35.
Uno Y, Momoi Y, Watari T, Goitsuka R, Tsujimoto H, et al. Malignant histiocytosis with multiple skin lesions in a dog. J Vet Med Sci. 1993; 55 (6): 1059-1061.

Valli E, Jacobs R, Parodi A, Verneau W, Moore P. Histiocytic sarcoma/malignant histiocytosis. En: Valli E. Histological classification of hematopoietic tumors of domestic animals. World Health Organization International Histological Classification of Tumors of Domestic Animals. Second Series Volumen 8. Washington (USA): Armed Forces Institute of Pathology \& American Registry of Pathology; 2002. p 120.

Willard M, Tvedten H (Eds). Macrophage Proliferative Disorders. En: Small animal clinical diagnosis by laboratory methods. 4 ed. (USA): Saunders. Elsevier; 2003. p 59-60.

Wilson DW, Dungworth DL. Tumors of the respiratory tract. En: Meuten DJ. Tumors in Domestic Animals. Iowa (USA): Iowa State Press; 2002. p 397-399. 